\title{
External Inflammatory Root Resorption: Management of a Tooth with hopeless Prognosis
}

\author{
${ }^{1} \mathrm{R}$ Abhilash, ${ }^{2}$ Jithin Balan, ${ }^{3} \mathrm{~K}$ Shoba, ${ }^{4} \mathrm{MR}$ Sreelakshmi
}

\begin{abstract}
The treatment of external root resorption and associated periodontal defect can be challenging to the most ingenious clinician. A correct diagnosis and an understanding of the etiology and dynamics of root resorption, which is the progressive loss of dentin and cementum through action of osteoclastic cells, are critical for effective management. The article describes the management of an external root resorption in maxillary central incisor where a combined endo-perio management strategy was implemented. Cone beam computed tomography was used as an adjunctive diagnostic aid. A combined approach using biodentine for root surface repair, bone graft, collagen membrane, and platelet-rich fibrin to address the associated osseous lesion appears to be viable modality in treatment of the same. After a follow-up period of 12 months, the patient was found to be asymptomatic. Postoperative radiographs also demonstrated satisfactory bone fill and arrest of the resorptive lesion.
\end{abstract}

Keywords: Biodentine, External root resorption, Osseous graft, Platelet-rich fibrin.

How to cite this article: Abhilash R, Balan J, Shoba K, Sreelakshmi MR. External Inflammatory Root Resorption: Management of a Tooth with hopeless Prognosis. Cons Dent Endod J 2017;2(1):24-27.

Source of support: Nil

Conflict of interest: None

\section{INTRODUCTION}

External root resorption is a progressive and destructive loss of tooth structure initiated by a mineralized or denuded area of root surface $e^{1,2}$ and is considered as a major resorptive condition without symptoms. ${ }^{3}$ The process involves interplay of inflammatory cells and hard tissue structures.

It is known to be initiated and maintained by many factors, ${ }^{1,4,5}$ but pulpal necrosis, trauma, periodontal

\footnotetext{
${ }^{1,4}$ Postgraduate Student, ${ }^{2}$ Senior Resident, ${ }^{3}$ Professor and Head

${ }^{1,3}$ Department of Conservative Dentistry and Endodontics Government Dental College, Kottayam, Kerala, India

${ }^{2,4}$ Department of Periodontics, Government Dental College Kottayam, Kerala, India

Corresponding Author: R Abhilash, Postgraduate Student Department of Conservative Dentistry and Endodontics Government Dental College, Kottayam, Kerala, India, Phone: +919447327542, e-mail: abhil8816@gmail.com
}

treatment, endodontic treatment, and tooth whitening agents are the most commonly described stimulants. ${ }^{6}$ Apart from local causes, systemic factors are involved in the etiology of external root resorption. ${ }^{7}$ Hyperparathyroidism, hypertension, and genetic disorder mainly contribute for the same.

Resorptive lesions can be most simply classified as external or internal. There have been many attempts at classification, of which the system proposed by Andreasen ${ }^{8}$ is widely acknowledged (Flow Chart 1).

Of the several types of external root resorption, the most common is the external inflammatory root resorption. ${ }^{9,10}$ If the resorptive defect is progressive and lead to communication between the oral cavity and root canal, surgical intervention ${ }^{11-14}$ will be necessary to remove the granulation tissue, to debride and repair the defect, and even to enable endodontic therapy.

\section{CASE REPORT}

A 13-year-old male patient reported to the Department of Conservative Dentistry and Endodontics, with a chief complaint of broken upper front teeth. The tooth had suffered previously from a traumatic injury 2 years back. His medical history was noncontributory.

On examination, Ellis class II fracture was noted in relation to 21 along with deep periodontal pocket of $13 \mathrm{~mm}$ with respect to mesiobuccal aspect of 21 . Other findings included grade I mobility of 21 and pain on vertical percussion for both 11 and 21 . Vitality tests revealed nonvital 11 and 21.

Flow Chart 1: Schematic diagram representing Andreasen's resorption

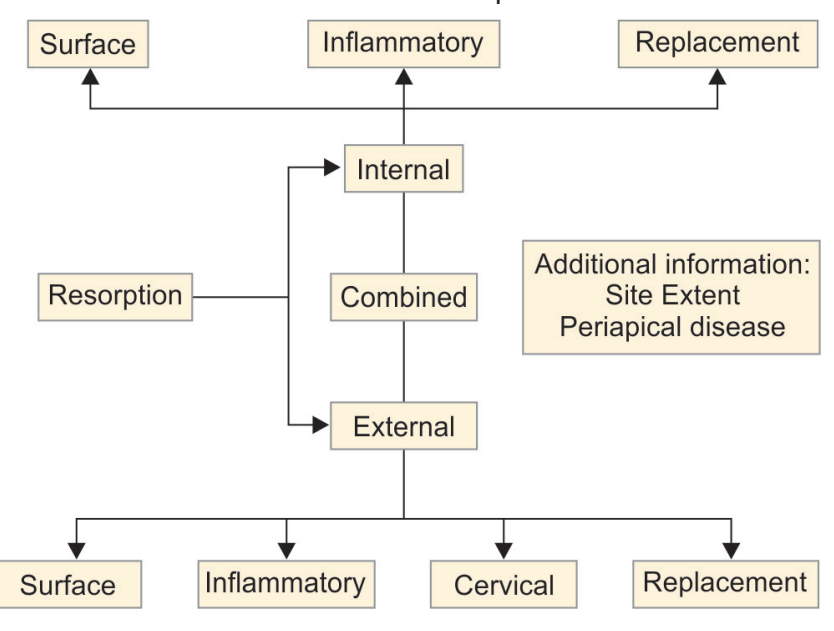



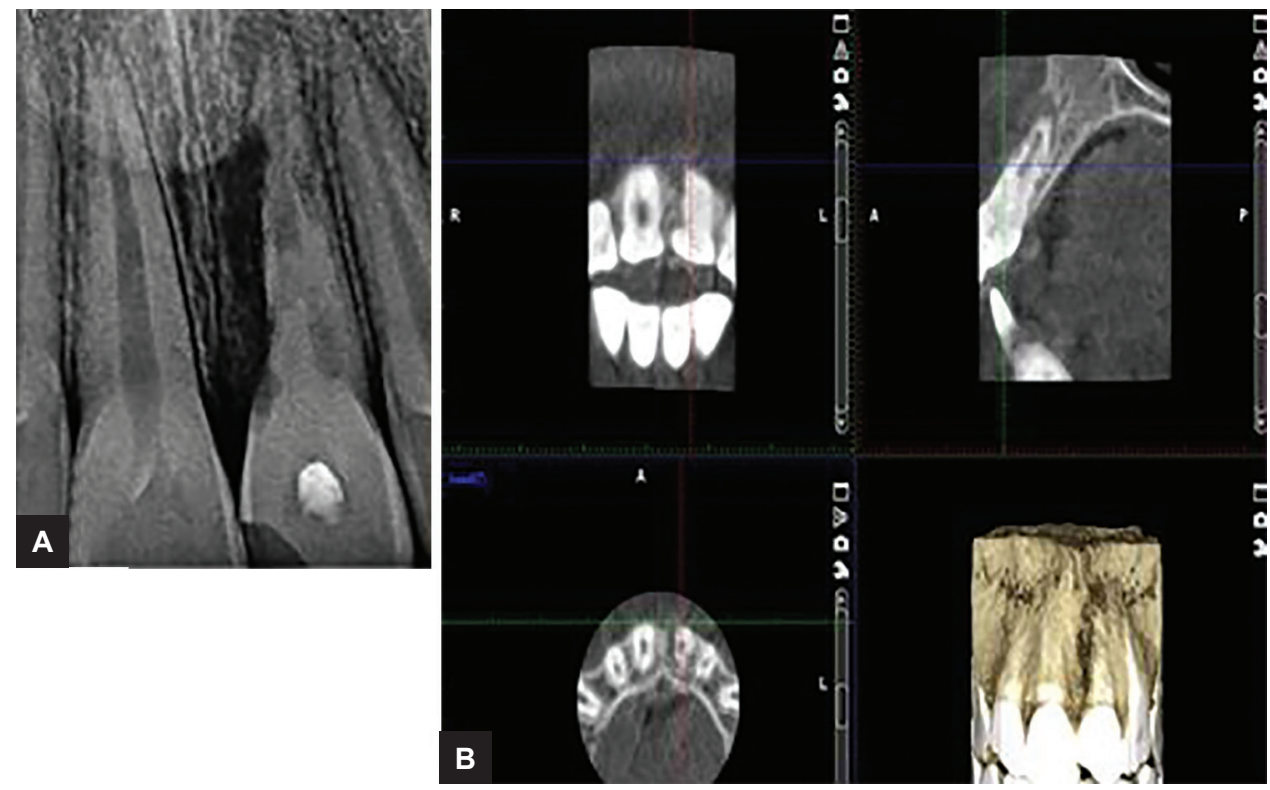

Figs 1A and B: (A) Intraoral periapical radiograph of involved tooth; and (B) CBCT sections of pathology

\section{PREOPERATIVE RADIOGRAPHIC FINDINGS}

\section{Intraoral periapical Radiograph}

The intraoral periapical radiograph revealed several resorptive bowl-shaped lesions on the external root surface of 21 combined with a radiolucent lesion around root apex of the involved tooth. Lesions were visible along entire root length of 21 extending along both mesial and distal root outlines, more marked with respect to mesial aspect. Apical periodontal widening was noted with respect to root of 11 (Fig. 1A).

\section{Cone Beam Computed Tomography}

Cone beam computed tomography (CBCT) has found vast application in the field of endodontics, particularly in resorption where it acts as an invaluable diagnostic aid in assessing the three-dimensional (3D) orientation and extent of resorptive lesion. ${ }^{15-18}$ The $3 \mathrm{D}$ extent of the lesion was precisely determined using the various sections of CBCT (3D, Planmeca, Proface). Coronal section revealed resorption involving mesial and distal root outlines along the entire root length and with irregular borders. The lesion communicates through and through at the junction of middle and apical third. Sagittal section shows bowl-shaped resorptive lesions along buccal and palatal root borders. This lesion communicates with root canal at apical third. Periapical radiolucency is evident in sagittal section. Buccal cortical plate discontinuity was observed in axial section (Fig. 1B).

\section{TREATMENT PROCEDURE}

Possible therapeutic procedures were discussed with and explained to the patient and it was decided to proceed with a combined endodontic, surgical, and restorative therapy. The treatment goals pertaining to the case included retaining the tooth, endodontic treatment and restoration of the radicular defect, regeneration of osseous deformity, and improved stability and esthetics.

Conventional root canal therapy was the choice of treatment for 11 . The root canal of 21 was negotiated with No. $10 \mathrm{~K}$ file and was debrided under rubber dam isolation. The canal was cleaned and shaped in a crown-down approach. Chlorhexidine being relatively nontoxic was used as irrigant. Calcium hydroxide (Metapex, METABIOMED Co. Ltd) was placed in the canal for 1 month.

Preliminary hematological investigations were done followed by thorough oral prophylaxis. Surgical site was anesthetized using 2\% lignocaine and 1:80,000 adrenaline (Lignox 2\% A, Warren, Indoco Remedies).

Crevicular incision was placed extending from distal aspect of 11 to distal aspect of 22. Vertical-releasing incisions were placed at the ends of crevicular incision. Fullthickness mucoperiosteal flap was reflected. Curettage of granulation tissue replacing the buccal cortical plate and occupying the resorption lacunae was performed. Resection of apical $5 \mathrm{~mm}$ of root segment was done to eliminate the lateral canals as well as resorptive lesion extending palatally, which were deemed unrestorable. The resected radicular margins were smoothed with a round bur while constantly irrigating with saline.

The resorptive site was sealed and the entire root canal was obturated using Biodentine ${ }^{\mathrm{TM}}$ (Septodont, SaintMaur-des-Fosse's, France) which was mixed according to the manufacturer's instructions. 

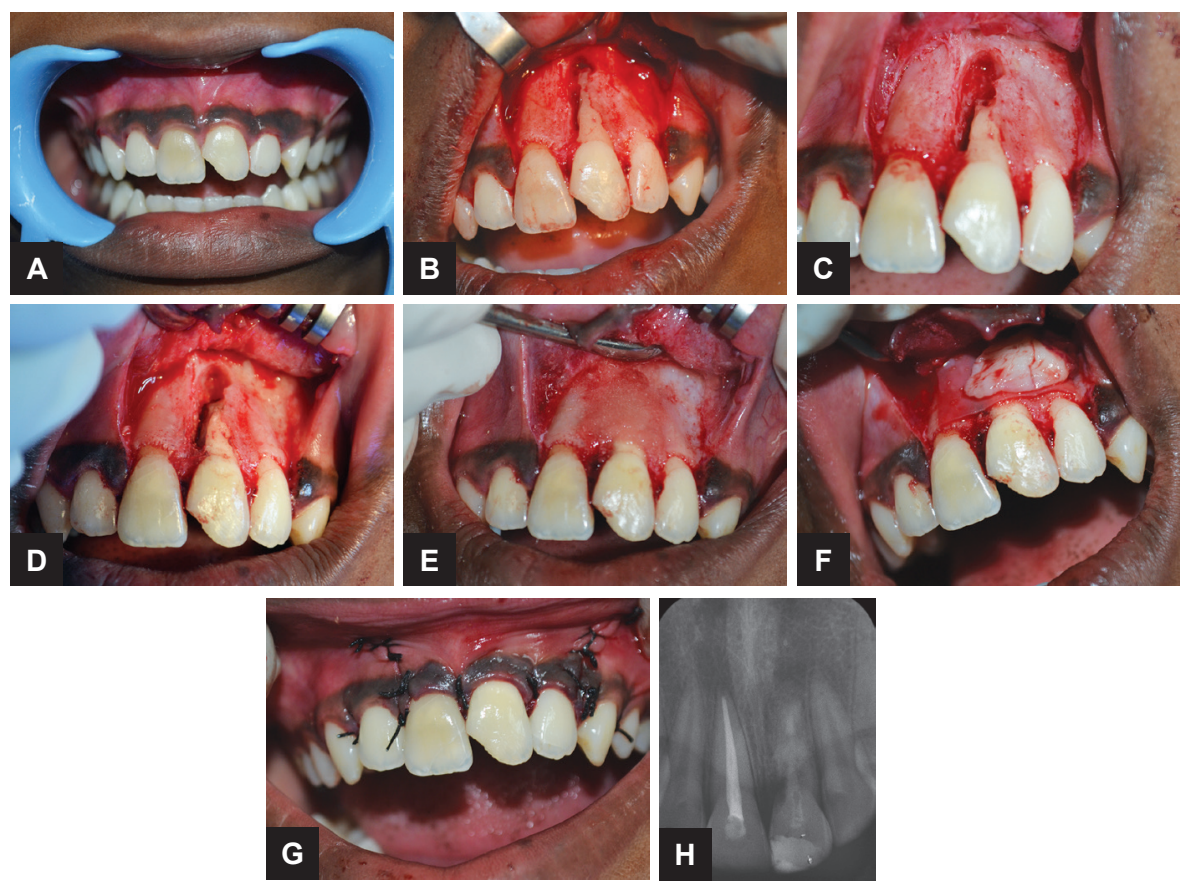

Figs 2A to H: (A) Preoperative; (B) mucoperiosteal flap reflection; (C) curettage and root end resection; $(D)$ sealing with biodentine; $(E)$ osseograft placed; $(F)$ collagen membrane and PRF in position; $(\mathrm{G})$ suturing; and $(\mathrm{H})$ 12-month postoperative radiograph

Freeze-dried demineralized xenograft (Osseograft, Advanced Biotech, India) was placed for osseous regeneration. Over this, bioresorbable collagen barrier membrane (Healguide, Advanced Biotech, India) was placed. Platelet-rich fibrin (PRF) which was prepared according to Choukroun's protocol further covered the membrane. The gingival tissue was stabilized using simple interrupted sutures and periodontal pack was placed (Coe Pack).

Patient was prescribed analgesics, antibiotics (Amoxicillin $500 \mathrm{mg}$ thrice daily for 5 days), $0.2 \%$ chlorhexidine mouthwash, and was advised soft diet. He was reviewed after 24 hours to evaluate presence of bleeding and intactness of sutures and pack (Fig. 2).

\section{Follow-up}

Patient is under regular follow-up and is asymptomatic; 12-month postoperative radiographs reveal satisfactory bone fill and arrest of resorptive lesion.

\section{DISCUSSION}

Even though a wide variety of factors are deemed to be causative for external root resorption, the most common is trauma, particularly in cases where injury results in pulpal necrosis and damage to root surface. Bacteria, bacterial by-products, and tissue breakdown products from within the root canal system stimulate inflammation in the adjacent periodontal tissue and lead to aggressive and progressive resorption of defect leading to external inflammatory root resorption. ${ }^{6}$
The diagnosis of external inflammatory root resorption has always been a dilemma in the field of endodontics. Newer diagnostic modalities like CBCT have added precision in determining the $3 \mathrm{D}$ orientation and exact extent of resorptive lesions.

Since its introduction, calcium hydroxide has been widely used in the treatment of external root resorption. ${ }^{19}$ It is a strong alkaline substance with a pH of 11 to 13 . It also has antimicrobial activity and tissue-dissolving ability, ${ }^{20}$ inhibits resorption, ${ }^{1}$ and induces repair by hard tissue formation. ${ }^{21,22}$

Biodentine is a novel tricalcium silicate-based material with setting time of less than 12 minutes, high mechanical strength, and excellent sealing ability. The calcium hydroxide ions stimulate the release of pyrophosphatase, alkaline phosphatase, and bone morphogenetic protein 2 , which enhances mineralization. ${ }^{23}$

This biointeractive material is a fast-setting alternative to conventional calcium silicate mineral trioxide aggregate (MTA)-like cement and does not require a two-step obturation unlike MTA. It also has a better consistency after mixing and offers ease of placement. ${ }^{23}$ Zhou et $\mathrm{al}^{24}$ have stated that this material can be safely used in procedures requiring close approximation with the periodontal tissue.

Two percent chlorhexidine was used as irrigant as it is placed to be more effective against Enterococcus faecalis than sodium hypochlorite. ${ }^{25}$ Use of osseograft which is osteoconductive along with collagen membrane and PRF enhances the regenerative potential. ${ }^{26}$ 


\section{CONCLUSION}

External root resorption jeopardizes the longevity of a tooth, causing its early loss. Therefore, early diagnosis is extremely crucial in the management. Sooner the treatment is done, less severe will be the long-term consequences of resorption. This defect demands intervention irrespective of etiology.

\section{REFERENCES}

1. Tronstad L. Root resorption - etiology, terminology and clinical manifestations. Endod Dent Traumatol 1988 Dec;4(6): 241-252.

2. Yilmaz HG, Kalender A, Cengiz E. Use of mineral trioxide aggregate in the treatment of invasive cervical resorption: a case report. J Endod 2010 Jan;36(1):160-163.

3. Benenati FW. Root resorption: types and treatment. Gen Dent 1997 Jan-Feb:45(1):42-45.

4. Karring T, Nyman S, Lindhe J, Sirirat M. Potentials for root résorption during periodontal wound healing. J Clin Periodontol 1984 Jan;11(1):41-52.

5. Hammarstrom L, Lindskog S. General morphological aspects of résorption of teeth and alveolar bone. Int Endod J 1985 Apr;18(2):93-108.

6. Fuss Z, Tsesis I, Lin S. Root resorption - diagnosis, classification and treatment choices based on stimulation factors. Dent Traumatol 2003 Aug;19(4):175-182.

7. Schätzle M, Tanner SD, Bosshardt DD. Progressive, generalized, apical idiopathic root resorption and hypercementosis. J Periodontol 2005 Nov;76(11):2002-2011.

8. Andreasen JO. Luxation of permanent teeth due to trauma. A clinical and radiographic follow-up study of 189 injured teeth. Scand J Dent Res 1970;78(3):273-286.

9. Kuo TC, Cheng YA, Lin CP. Clinical management of severe external root resorption: A case report. Chin Dent J 2005;24(1):59-63.

10. Sak M, Radecka M, Karpi ski TM. Tooth root resorption: etiopathogenesis and classification. Micro Med 2016 Feb;4(1): 21-31.

11. Frank AL, Bakland LK. Nonendodontic therapy for supraosseous extracanal invasive resorption. J Endod 1987 Jul;13(7): 348-355.

12. Rabie G, Trope M, Tronstad L. Treatment of a maxillary canine with external inflammatory root resorption. J Endod 1988 Feb;14(2):101-105.
13. Friedman S. Surgical-restorative treatment of bleachingrelated external root resorption. Endod Dent Traumatol 1989 Feb;5(1):63-67.

14. Isidor F, Stokholm R. A case of progressive external root resorption treated with surgical exposure and composite restoration. Endod Dent Traumatol 1992 Oct;8(5):219-222.

15. Scarfe WC, Levin MD, Gane D, Farman AG. Use of cone beam computed tomography in endodontics. Int J Dent 2009;2009:634567.

16. Patel S, Kanagasingam S, Mannocci F. Cone beam computed tomography (CBCT) in endodontics. Dent Update 2010 JulAug;37(6):373-379.

17. Cohenca N, Simon JH, Mathur A, Malfaz JM. Clinical indications for digital imaging in dento-alveolar trauma. Part 2: root resorption. Dent Traumatol 2007 Apr;23(2):105-113.

18. Patel S, Dawood A. The use of cone beam computed tomography in the management of external cervical resorption lesions. Int Endod J 2007 Sep;40(9):730-737.

19. Cvek, M. Endodontic management of traumatised teeth. In: Andreasen, JO.; Andreasen, FM., editors. Textbook and color atlas of traumatic injuries to the teeth. 3rd ed. Copenhagen: Munskgaard; 1994. p. 560-561.

20. Andersen M, Lund A, Andreasen JO, Andreasen FM. In vitro solubility of human pulp tissue in calcium hydroxide and sodium hypochlorite. Endod Dent Traumatol 1992 Jun;8(3):104-108.

21. Foreman PC, Barnes F. A review of calcium hydroxide. Int Endod J PQ 1990:23:283-297.

22. Siqueira JF Jr, Lopes HP. Mechanisms of antimicrobial activity of calcium hydroxide: a critical review. Int Endod J 1999 Sep;32(5):361-369.

23. Maria Giovanna Gandolfi, Francesco Siboni, Antonella Polimeni, Maurizio Bossu, Francesco Riccitiello, Sandro Rengo and Carlo Prati. In vitro screening of the apatite-forming ability, biointeractivity and physical properties of a tricalcium silicate material for endodontics and restorative dentistry. Dent J 2013;1(4):41-60.

24. Zhou HM, Shen Y, Wang ZJ, Li L, Zheng YF, Häkkinen L, Haapasalo M. In vitro cytotoxicity evaluation of a novel root repair material. J Endod 2013 Apr;39(4):478-483.

25. Mohammadi $Z$, Abbott PV. The properties and applications of chlorhexidine in endodontics. Int Endod J 2009 Apr;42(4): 288-302.

26. Dohan Ehrenfest DM, Del Corso M, Diss A, Mouhyi J, Charrier JB. Three-dimensional architecture and cell composition of a Choukroun's platelet-rich fibrin clot and membrane. J Periodontol 2010 Apr;81(4):546-555. 